\title{
Enhancing Ministry Service Provision: Adoptive Families' Capacity to Care for Children and Youth with Special Needs
}

\author{
Christina Yee* \\ University of Victoria \\ cyee@uvic.ca
}

\begin{abstract}
This literature review was conducted to explore what elements contribute to the success and disruption of children with special needs who are adopted into prospective families. Five prevailing themes emerged as important considerations when placing children and youth who are waiting to be adopted. These themes include: the characteristics of the child, the characteristics of the adoptive family, sibling placements, agency practices, and most importantly access to pre- and post-adoption supports and services. A general consensus among the voices of professionals and adoptive families in this area of practice concerns the significance of supporting families before, during, and after the placement of children and youth with special needs to ensure permanency of placements. Identifying service needs and gaps in service delivery are therefore essential to ensuring safe, healthy, and successful adoptive experiences for children and youth with special needs. The findings of this report pose important implications for the adoption sector of
\end{abstract}

"This research project was sponsored by the B.C. Ministry of Children and Family Development (MCFD) and was completed under the supervision of Dr. Gord Miller, from the University of Victoria, and sponsor's Wendy Norris and Renaa Bacy from MCFD. The author would like to thank and acknowledge the Jamie Cassels Undergraduate Research Award through the Office of the Vice President Academic and the Learning and Teaching Centre at the University of Victoria for supporting her research. Finally, the author would like to extend her sincerest gratitude to her peers, professors, sponsors, friends, and family who without their support this work would have not been possible. 
the Ministry of Children and Family Development in the service provision of special needs adoptions.

Keywords: adoptions; special needs; children and youth; success and disruption; service needs; permanency; MCFD; service provision

\section{INTRODUCTION}

I $\mathrm{N}$ THE FIELD OF CHILD WELFARE and adoption, the concept "special needs" may have broad definitions. It can refer to "any child who is difficult to place as a result of physical, mental, or behavioral disability, race, age, or membership in a sibling group" (Perry \& Henry, 2009, p. 540). According to the B.C. Ministry of Children and Family Development (MCFD) (2014), there are approximately 1000 children in the permanent care of the Ministry who are waiting to be adopted at any given point in time. "Disruption rates reported for special-needs adoptions range from $8 \%$ to 47.4\%" (Borgman 1981; Kadushin 1974, as cited in Westhues \& Cohen, 1990, p. 143). The purpose of this report is to help illuminate the complex interplay of factors that influence adoption outcomes for children and youth with special needs following their placement into families. These factors are defined as: the characteristics of the child, the characteristics of the adoptive family, sibling placements, agency practices, and access to pre- and post-adoptions supports and services. The hope is that by identifying these emerging patterns in research, best practice decisions in service provision will be made regarding special needs adoptions. This literature review is intended to aid service providers when looking at placement decisions. In addition to ministry workers, this research has interdisciplinary significance for professionals in social work, nursing, counselling, psychology, psychiatry and other related disciplines.

The paper begins with an overview of the literature search strategy. Next, findings from the review are presented. Finally, the research is discussed in terms of its implications and significance to the MCFD, as well as to the children, youth, and families with special needs. The paper concludes with a discussion of limitations and 
recommendations for future research.

\section{LITERATURE SEARCH STRATEGY}

The purpose of this literature review is to determine what factors contribute to or disrupt the success of adoption placements of children and youth with special needs. This review involved keyword searches of online databases (Academic Search Complete, PsycINFO, and Google Scholar), additional searches for other studies, screening of abstracts, assessments of the methodological strength of these studies and, finally, integration of the findings. The search results are summarized in tables 1-3. The literature search process included the following major steps:

- Development of keywords and search strategies

- On-line searches of databases for potentially relevant articles

- Screening of abstracts for relevance and usefulness

- Review of the references sections of articles

- Review of government departments and related links for additional studies and or unpublished documents

Table 1: Database: Academic Search Complete

\begin{tabular}{ll}
\hline & \\
Search terms & Results \\
\hline Special needs + adoptions & 30 of 345 \\
Special needs + adoptions + children & 21 of 225 \\
Special needs adoptions + Canada & 1 of 13 \\
Special needs adoptions + permanency & 3 of 12 \\
Special needs adoptions + foster care & 4 of 59 \\
$\begin{array}{l}\text { Special needs children + adoption outcomes } \\
\text { Adoptive families + special needs children }\end{array}$ & 15 of 82 \\
$\begin{array}{l}\text { Adoptive families } \\
+ \text { caring for children with special needs }\end{array}$ & 2 of 6 \\
Characteristics of adoptive family & \\
+ special needs adoptions & 3 of 18 \\
\hline
\end{tabular}




\begin{tabular}{ll} 
Search terms & Results \\
\hline Special needs + adoptions & 14 of 231 \\
Special needs + children + adoptions & 12 of 171 \\
Adoption outcomes + special needs & 3 of 46 \\
Adoptive parents + special needs children & 8 of 91 \\
Permanency + special needs adoptions & 1 of 5 \\
Characteristics of adoptive families & \\
+ special needs children & 8 of 29 \\
Agency practices + special needs adoptions & 1 of 6 \\
\hline
\end{tabular}

Table 3: Database: Google Scholar

\begin{tabular}{ll} 
Search terms & Results \\
\hline $\begin{array}{l}\text { Adoptive families + capacity to care } \\
\text { + children with special needs }\end{array}$ & 11 of 33,000 \\
$\begin{array}{l}\text { Adoption outcomes + children with } \\
\text { special needs }\end{array}$ & 14 of 504,000 \\
$\begin{array}{l}\text { Permanency + adoptive families } \\
\text { + children with special needs }\end{array}$ & 22 of 11,900 \\
$\begin{array}{l}\text { Adoptive families + children with } \\
\text { special needs + disruption }\end{array}$ & 25 of 20,700 \\
$\begin{array}{l}\text { Success + disruption + adoption } \\
+ \text { special needs children }\end{array}$ & 12 of 81,000 \\
\hline
\end{tabular}

\section{Summary OF ELEMENTS THAT INFLUENCE ADOPTION OUTCOMES}

From the broad sample, ten articles were selected for analysis based on their cumulative rating according to the criteria below: 
- Rating 1: Provides an abundance of data to document factors that contribute to the success or disruption of adoption placements. Research and or evaluative designs were present in the literature.

- Rating 2: Practice implications are identified, well-supported by credible research, and are sustainable in nature.

- Rating 3: The information provided in the report has been replicated and can be found in one or more other articles.

The articles that were awarded all three ratings were considered $E x$ emplary, an article that was awarded two ratings was considered Probably Effective and an article with just one rating was considered Possibly Effective. Table 4 presents a summary of the ratings of articles in the sample.

Table 4: Article sample ratings

\begin{tabular}{ll}
\hline & Rating \\
\hline $\begin{array}{l}\text { Denby, Alford, \& Ayala (2011) } \\
\text { Perry \& Henry (2009) }\end{array}$ & $\begin{array}{l}\text { Exemplary } \\
\text { Exemplary }\end{array}$ \\
$\begin{array}{l}\text { Zosky, Howard, Smith, Howard, } \\
\text { \& Shelvin (2005) }\end{array}$ & Exemplary \\
Reilly \& Platz (2004) & Exemplary \\
Egbert \& Lamont (2004) & Exemplary \\
Erich \& Leung (2002) & Probably effective \\
McGlone, Santos, Kazama, Fong, & \\
\& Mueller (2002) & Probably effective \\
Rosenthal \& Groze (1994) & Probably effective \\
Westhues \& Cohen (1990) & Probably effective \\
Barth, Berry, Yoshikami, Goodfield, & \\
\& Carson (1988) & Probably effective \\
\hline
\end{tabular}

Denby, Alford, and Ayala (2011) use qualitative inquiry to learn from prospective parents of nine different families their experiences of the adoption process including their motivations, expectations, prepa- 
ration, and experiences. Perry and Henry (2009) identify elements that make the placements of children with special needs successful, including adoptive parent expectations, experience with disabilities, preparedness and education needs, resources, and support systems. Zosky, Howard, Smith, Howard, and Shelvin (2005) study the aid of adoption preservation services in the prevention of negative adoption outcomes. Reilly and Platz (2004) explore the post-adoptive service needs of families adopting children with special needs. Two hundred forty-nine $(\mathrm{N}=249)$ special needs adoptive families representing 373 children from the state of Nevada responded to a mailed survey to identify unmet service needs and the relationship of post-adoption service utilization to positive adoption outcomes. Egbert and Lamont (2004) utilize both qualitative and quantitative data in a study to determine what factors contribute to adoptive parents' preparation for adopting children with special needs. Erich and Leung (2002) address the impact of previous types of abuse experienced by children and sibling adoption on family functioning. McGlone, Santos, Kazama, Fong, and Mueller (2002) focus on understanding the nature and extent of parental stress among adoptive parents of children with special needs; five stress categories were identified: child characteristics, parent-child interactions, family cohesion, parental adjustment, and adoptions service issues. Rosenthal and Groze (1994) conduct a longitudinal study on adoptive families caring for children with special needs and assessing change on several measures of adoption outcome. Westhues and Cohen (1990) analyze the differences in functioning between families able to sustain special-needs placements and families in which they disrupted. Barth, Berry, Yoshikami, Goodfield, and Carson (1988) examine the complexities of older child adoptions and sibling placements as means of understanding why adoption disruptions occur. 


\section{AnAlysis}

\section{Characteristics of the child}

Articles analyzed: Egbert \& Lamont, 2004; Westhues \& Cohen, 1990; Perry \& Henry, 2009; Zosky, Howard, Smith, Howard, \& Shelvin, 2005; Barth, Berry, Yoshikami, Goodfield, \& Carson, 1988; Erich \& Leung, 2002

The literature indicates that several factors may influence special needs adoption outcomes. One factor is the age at which the child or youth is taken into care, and the age at which he or she is placed for adoption. Older children (defined as those above the age of three) are more likely to have had multiple placements throughout their lives than younger children. It can also be more difficult to find placements for older children, because most adoptive parents prefer infants and younger children. Children of varying ages may have histories of emotional, physical, and sexual abuse and neglect. These experiences may contribute to challenging behaviours, such as acting out, lying, tantrums, defiance, profanity, vandalism, aggression, drug use, and attachment difficulties that result in adoption disruptions. Other emotional and psychological challenges, such as eating disorders and suicide threats, may also play a role in unsuccessful placements. Prenatal or postnatal exposure to substance abuse during critical points in development can impact a child's ability to adapt, their mood, behavioural nature, distractibility, and acceptability. These are additional behavioural challenges that adoptive parents may face in the adoption setting.

\section{Characteristics of the adoptive family}

Articles analyzed: Denby, Alford, \& Ayala, 2011; McGlone, Santos, Kazama, Fong, \& Mueller, 2002; Rosenthal \& Groze, 1994; Egbert \& Lamont, 2004; Perry \& Henry, 2009 
Adoption outcomes are further influenced by various characteristics of adoptive families. Parental preparation and readiness for adoption are defined by the caregivers' expectation for the adoption and their understanding of the reality of caring for a child with special needs. Furthermore, practical experiences and personality attributes of adoptive parents contribute to their understanding of the complexities and challenges of caring for a child or youth with special needs. For example, practical experiences, such as personal experience and or work experience with physical, mental, behavioural, and or cognitive disabilities, will enhance one's ability to empathize with the task of caring for a child with extra support needs. Personality attributes that may lend to better care include the ability to accept a child's condition and differing abilities, flexibility, adaptability, patience, commitment, and level of social, familial, and professional support. Motivational desires to provide permanent care for a child and to provide the child with nurturance, love, and stability are more likely to increase adoption success. Furthermore, parents who are of an older age at the time of adoption are perceived to be better prepared for the adoption experience due to potential experience in facing and resolving crises, in addition to their overall maturity level. That being said, overall positive physical and mental health of adoptive parents will lead to better outcomes. Foster parents experience greater levels of preparedness in comparison to newly adopting parents as a result of previous experiences. A family's ethnic background, cultural beliefs and values may influence family perspective and parenting approaches in caring for a child or youth with special needs. Moreover, religious affiliation has been associated with successful placements. Finally, financial stability influences a family's willingness and ability to access professional supports and services when they are needed.

\section{Sibling placements}

Articles analyzed: Erich \& Leung, 2002; Barth, Berry, Yoshikami, Goodfield, \& Carson, 1988 
Sibling placements refers to the placement of a group of birth siblings together in a single placement. This is a common practice that is highly ideal as it helps to regulate attachment disruptions from birth parents; however, research shows that sibling adoptions are associated with a greater likelihood of adoption disruption. It is also difficult to find adoptive families who are willing to adopt more than one child, as raising sibling groups require additional energy, time, finances, and skills which may affect the quality and stability of family functioning.

\section{Agency practices}

Articles analyzed:Westhues \& Cohen, 1990; Egbert \& Lamont, 2004; Reilly \& Platz, 2004; Zosky, Howard, Smith, Howard, \& Shelvin, 2005

Placements are most likely to disrupt when children have had multiple placements throughout their lives, have experienced a longer break between being freed for adoption and being placed, and when children have had different workers involved in the various aspects of adoption work. Successful placements result from positive and collaborative parent-agency relationships where open communication and information is exchanged about the child's history and the adoption process. This allows parents time to develop feelings of preparedness to care for a child or youth with special needs to adapt to their role as an adoptive parent. A positive parent-agency relationship can facilitate better obtainment of information and training that can better inform parents of the adoption process and expected challenges that may arise.

Prior to adoption placements, there are certain practices which an agency can employ that may increase adoption success. Providing the family with adequate information about the child is key. This entails completing thorough evaluations of the child before placement, identifying any effects of prenatal substance exposure and the severity of medical and behavioural challenges, and communicating these to prospective families. Following placements, it is important to con- 
tinue to support families by conducting follow-ups and providing access to ongoing educational opportunities to facilitate parents' continual acquisition of the support, expertise, and skills necessary to understand and manage their children's emotional and behavioural challenges.

\section{Access to supports and services}

Articles analyzed:Reilly \& Platz, 2004; Zosky, Howard, Smith, Howard, \& Shelvin, 2005; Egbert \& Lamont, 2004; Perry \& Henry, 2009

A common theme across the literature was the significance in which an adoptive families' access to pre- and post-adoption supports and services played in determining adoption outcomes. Placements are more likely to succeed when parents receive pre-adoption education and training in caring for children and youth with special needs. Depending on the child or youth, providing families with specialized training that caters to the unique difference of each child and youth can also increase levels of preparedness. Moreover, providing parents with strategies for coping and dealing with stressful situations that may arise and connecting them with health professionals will ultimately enhance adoption success. After placement decisions have been made, agencies can continue to provide ongoing financial, medical, emotional, and respite support for families. Post-adoption, families also benefit from connecting with other adoptive families of children with special needs who share the same experiences as they do.

\section{Discussion}

\section{Factors in successful placements}

Research provides evidence that there have been both long-term successes as well as failures in the adoption placements of children and youth with special needs (Perry \& Henry, 2009). The important task is 
to understand what contributes to successful and unsuccessful placements, to explore what makes for good therapeutic relationships between adoptive children and families, and to determine the agency's role in supporting families during this process. Five prevailing factors surfaced from the literature reviewed that can be considered imperative when placing children and youth with special needs into prospective adoptive families. The themes were not identified in all pieces of work that were reviewed, but rather amalgamated by the researcher of this report as common patterns and themes found amongst the existing research in this area of practice. As illustrated in Figure 1, these key factors consist of: the characteristics of the child, the characteristics of the adoptive family, sibling placements, agency practices, and the families' access to pre- and post-adoption supports and services. Each of these factors are then elaborated upon in order to explain what is specifically entailed.

Adoptive families from many walks of life have the capacity to provide good permanent homes to children and youth with special needs when they are adequately prepared and have been provided with the supports and services necessary for success. As divulged in the characteristics of the child, the process of adopting and placing a child or youth with special needs is a complex, stressful, and delicate process. This process is complicated by the desire to avoid adoption dissolution given the fragility of relationship history and frequent experiences with attachment disruptions experienced by children in the child welfare system (Zosky, Howard, Smith, Howard, \& Shelvin, 2005). For adoptive families and parents, special-needs adoptions are generally believed to be stressful and challenging life processes (Barth \& Berry, 1988; Groze, 1996; Groze \& Gruenewald, 1991). In order to cope with the stressors and challenges faced by adoptive families, special needs families rely on a host of available resources and supports before, during, and after placements. Even after placements have been made with best practices to ensuring adoptive families' levels of preparedness for adoption, challenges post-adoption can continue to arise and manifest due to the escalation of new demands and changes to the overall family system (McGlone, Santos, Kazama, 
Figure 1: Elements that influence special needs adoptions. This context chart illustrates the five prevailing themes that contribute to the success or disruption of adoption outcomes. Branching off of each one of the themes are elements that make up each of these themes.

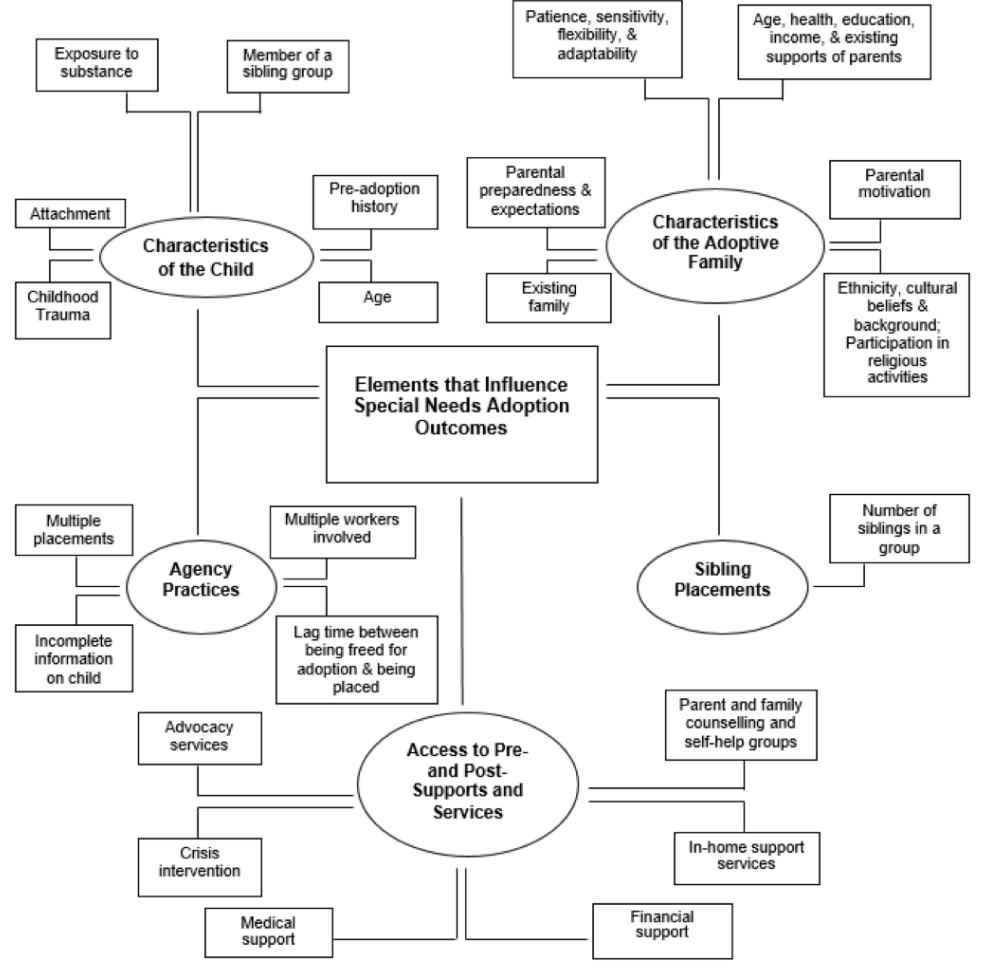


Fong, \& Mueller, 2002). Some of the challenges that adoptive families encounter include: difficulties in establishing family cohesion, navigation of the challenges of obtaining required services, increased demands resulting in decreased personal time, and feelings of grief resulting from the loss of "expected" child and life goals (Perry \& Henry, 2009; McGlone et al., 2002). In a study done by Reilly and Platz (2004), financial and medical support is the most frequently cited need by parents who are generally satisfied with services in this area (Zosky et al., 2005). Counseling and in-home supports were reported as necessities that were frequently unmet. Other positive influences on family functioning include support groups with other adoptive family, parent and child support and activity groups, services to help families plan for their child's future, family preservation services, and adoption-sensitive mental health services (Rosenthal, Groze, \& Morgan, 1996). Overall, research suggests that access to pre- and postadoption supports and services are regarded by adoptive families as an instrumental contribution to the long-term success of placements.

Inherent to the population of children and youth who are waiting to be adopted in the child welfare system are a set of risk factors that can negatively affect adoption placements unless families are wellinformed and adequately prepared for the potential challenges that may arise (Simmel, 2007). "In the field of foster care and adoption, the term "special needs" can refer to any child who is difficult to place as a result of physical, mental, or behavioral disability, race, age, or membership in a sibling group" (Perry \& Henry, 2009, p. 540). Children who are adopted through the child welfare system are often significantly challenged by adjustment issues; they may have unique psychological scars and relational deficits as a result of their past experiences, and these scars and deficits may vary widely (Zosky, Howard, Smith, Howard, \& Shelvin, 2005). The characteristics of the child can include both internal and external problematic behaviours and both types of behaviour may indeed add to the stress placed upon adoptive families. Existing histories of physical, emotional, and or sexual abuse and neglect may also greatly affect a child's behaviour as well as the manner in which this behaviour is exhibited in a new family 
setting. Additionally, children and youth in the child welfare system often share common experiences of attachment difficulties, namely the experience of coping with the loss of biological parents as well as the loss of any previous foster parents or adoptive parents where attachments may have been formed (Zosky et al., 2005). Attachment disruptions pose significant challenges to the adoptive family as well as to the child's ability to bond and develop a relationship; attachment disruptions are manifested as disruptions in interpersonal skills (Smith, Howard, \& Monroe, 2000, as cited in Zosky et al., 2005). The research here demonstrates that adoptive parents experience stress due to these communication difficulties and the lack of disclosure and withdrawal has been identified as problematic (McGlone, Santos, Kazama, Fong, \& Mueller, 2002).

Adoptive families and adoptee children and youth can come from anywhere amongst a variety of unique backgrounds and experiences in life. It is essential, therefore, to form an understanding of all these possible combinations of characteristics, both in the children and in the adoptive families, in order to evaluate the "goodness of fit" between them. Although some characteristics of adoptive families have long been identified as contributing factors to the success of adoption placements, it is important to note that the characteristics of adoptive parents have begun to broaden over the years (Rosenthal, Groze, \& Curiel, 1990; Schwartz, 2008; Wright \& Flynn, 2006, as cited in Denby, Alford, \& Ayala, 2011). Single parents, same-sex couples, minority parents, and unmarried live-in partners have all been recognized as distinctive characteristics of prospective adoptive families (Schwartz, 2008, as cited in Denby et al., 2011). But while every one of these circumstances can have an effect on adoption success, it is parental preparedness most of all which seems to affect the outcome of caring for a child or youth with special needs. Parental preparedness can alternatively be defined as a sense of readiness, and this sense of readiness is derived in part from: the age of the caregivers, their socioeconomic status, their ability to cope, their health and well-being, their cultural background, their family composition and functioning, and the levels of support that adoptive families receive (Perry \& Henry, 2009; 
Wessthues \& Cohen, 1990). Two other key measures of preparedness are the adoptive parents' expectations for the adoption as well as their understanding of the reality of parenting a child or youth with complex needs (Egbert \& Lamont, 2004). It is important to recognize the increase of stress and strain that adoptive families can face after adoption; thus, assessing a prospective families' level of preparedness in multiple domains is crucial. An overload in parenting stress can lead to an inability to cope, which in turn may result in adoption disruption.

According to the Adoptive Families Association of British Columbia (2014), more than $50 \%$ of B.C.'s waiting children are part of a sibling group that must be adopted together. What becomes apparent, and problematic, is that a dearth of literature exists regarding sibling placements and their impact upon either an adoptive family's functioning or upon the post-adoptive behavior of the children (Erich \& Leung, 2002). Barth, Berry, Yoshikami, Goodfield, and Carson (1988) have noted that although it is preferable to place siblings together in the same adoptive family, placement disruption often occurs as a result. In the best interests of those children, sibling placements help better manage the effects of attachment disruption from biological parents (Erich \& Leung, 2002). However, such sibling placements require additional time, energy, and skills on the part of adoptive parents. These additional requirements often result in additional stress which may in turn have adverse effects on family functioning and placement stability. Another type of situation parallel to sibling placements is the example of multiple special needs children, not part of a sibling group, being placed with adoptive families. The existing research in this particular area of special needs adoption is limited; however, in one study conducted by Glidden, Flaherty, and McGlone (2000), larger families (five or more) rearing multiple adopted children with special needs enjoyed greater levels of parental satisfaction and adjustment in comparison to conventionally-sized families (four or fewer).

There are certain practices that an agency can employ to contribute to the success of adoption outcomes; these practices can greatly 
help to ensure the permanency of adoption placements for children and youth with special needs. Research suggests that practice variables play an influential role in the success and failure of special needs adoptions. In particular, practice variables are effective as a way of preparing adoptive parents in having realistic expectations regarding adoption and also by providing families with pre- and postadoption supports. As well, gaining an understanding of some of the challenges that agencies have historically presented to adoptive families can help to guide the development of areas needed for further support. This gaining of historical understanding has proven useful in both successful and disruptive adoption experiences. In respect to agency practices, "several studies link inadequate or inaccurate background information on the adoptive child to increased risk of disruption or lower parental satisfaction with the adoption" (Urban Systems, 1985, as cited in Rosenthal, Groze, \& Morgan, 1996, p. 164; Barth \& Berry, 1988; Rosenthal \& Groze, 1992; Schmidt, Rosenthal, \& Bombeck, 1988). Other practices that have been associated with adoption disruption include barriers to post-placement services, and insufficient pre-adoptive training (Groze, 1994, 1995, as cited in Reilly \& Platz, 2004). Measuring parental satisfaction with the adoption process is one of several ways to determine the positive or negative outcomes of special needs adoptions (Reilly \& Platz, 2004). Practice issues may further contribute to disruptions when: children have had multiple placements throughout their lives, have experienced a longer break between being freed for adoption and being placed, and those who have had different workers involved in the various aspects of adoption work (Westhues \& Cohen, 1990).

\section{Research implications}

The findings elucidated from this literature review pose important implications for the adoption sector of the Ministry of Children and Family Development. These findings are highly relevant to the ministry's service provision when placing children and youth with special needs. Congruent across almost all domains of the literature re- 
viewed is the evidence, in regard to special needs adoptions, for providing ample pre- and post-adoption supports and services. These supports and services should be tailored to the unique needs of each adoptive family, child or youth. In support of this conclusion, we see that successful adoption outcomes are positively correlated with a parent's preparedness for adoption (Egbert \& Lamont, 2004). We can conclude then, that parental preparedness is the most critical characteristic of prospective adoptive parents. Preparation enhances coping, which in turn supports the adoptive family's ability to adapt to their new family system and effectively address issues that arise in the adoption setting (Egbert \& Lamont, 2004). Ultimately, this requires agency practices that work to best support adoptive families in succeeding in their adoption; these are practices that provide sufficient information regarding the child, and offer services both during and long after placements in order to maximize sustainability. Therefore, accurate identification of the characteristics possessed by children or youth in the child welfare system is of great importance. Such proper identification informs the adoptive parents of what to expect of their child and it correctly gauges whether prospective parents are prepared to handle such challenges. Furthermore, given the varying and unique characteristics that children, youth, and families' exhibit, it is important to not just define "goodness of fit" along the lines of physical attributes, but to also factor in the parents' experiences and motivations (Denby, Alford, \& Ayala, 2011).

Lived experiences that adoptive families have provided us with have helped us to gain invaluable knowledge. We have learned that "post-adoption services can be instrumental in helping parents weather the storm of caring for a special needs adopted child and in the prevention of adoption failure" (Zosky, Howard, Smith, Howard, \& Shelvin, 2005 , p. 2). With that said, important questions still need to be asked in this area of practice: what are the barriers to providing families with consistent supports and services, before, during, and after placements? Why has this been expressed in the literature as an ongoing need? In order to support adoptive families, and their adopted children and youth in this area, what can we do to overcome these 
barriers and work around any obstacles that may be in the way? It is evident that further research is required in addressing and taking action upon these gaps in service delivery, especially now that they have been identified as critical needs. Why is there a lack of published literature in this area pertaining to the Canadian population of children and youth with special needs waiting to be adopted? With an overrepresentation of Indigenous children and youth in the child welfare system in Canada, are adoptive parents educated when there is a disparity in culture between the child or youth and the adoptive family? If so, how are they educated? Other directions for future research resulting from the literature review suggest the need to further explore sibling placements and its impact on adoption outcomes given the substantial number of sibling groups who are waiting to be adopted in Canada. As service providers, it is essential to continue to ask these questions and others that may arise in order to identify and address any service needs that may be lacking and gaps in service delivery that are present.

To further expand the literary review's scope in the future, it may be valuable to look into evaluation and assessment models concerning special needs adoptions that already exist and consider how they might inform further research in this area. Berry, Propp, and Martens (2007) explored the use of intensive family preservations services (IFPS) with adoptive families. In their findings, IFPS models have promising outcomes for families who have problems with child behaviour (Berry, Propp, \& Martens, 2007). The use of multiple regression analyses helped determine factors that were predictive of the family's ability to remain intact after a certain period of time after services were seized. Conversely, other researchers such as Yampolskaya, Sharrock, Armstrong, Strozier, and Swanke (2014) used latent class analysis to determine subgroups of children who have served in out-of-home care. These subgroups helped to understand the various profiles of children that influence permanency outcomes. Consideration and utilization of such models and tools for future research will enrich the understanding of the needs of children, youth and families in this area of practice. 


\section{Research limitations}

A literature review of this nature is, of course, limited to what research is available. Pointedly, there is still not enough research available on the factors that contribute to the success or disruption of adopting children and youth with special needs. It is important to acknowledge that no literary search criteria was used specifically to search "Best Practices" regarding data collection methodologies that are currently used to assess and identify the needs for children with special needs. Additionally, certain factors which influence adoption outcomes, such as the impact of single parent adoptive families as opposed to adoptive families with two parents, are under-studied as well. This want of material limited the findings of this report. Likewise, employing a search methodology was necessary in order to conduct this type of research, but search methodologies have their own constraints. The geographic scope of this literature review, as well, presents limitations; the majority of the studies and articles that the researcher found and reviewed were established in the United States. Consequently, the findings may not be completely generalizable to other populations, including Canada's. In addition, the research that was utilized to inform this literature review was chosen and determined solely by the researcher's evaluation of the breadth of the articles. Finally, the research was obtained and retrieved from only a select few of the available on-line databases.

\section{CONCLUSION}

The general consensus of professionals and adoptive families in this area of practice is that there is a fundamental need to support families before, during, and after the placement of children and youth with special needs. Crucial to pre-adoptive placement supports is the ability to provide families with a thorough overview of the background of their child. This overview includes what the characteristics of the child are, what challenges adoptive families should expect, and the provision of specialized training to deal with challenges as they arise. Additionally, the encouragement of preparation on the part of the 
adoptive family and making a network of support available to them both contribute greatly to successful outcomes. Moreover, through accurately assessing parenting experiences and the overall characteristics of adoptive parents, and by comprehensively evaluating the level of children's needs, agencies can successfully determine which placements will allow a "goodness of fit" between the two. By utilizing these practices, agencies maximize adoption success (Egbert \& Lamont, 2004). While placement decisions are being made, and in their aftermath, it is important to continue to support families and address emerging issues; indeed these issues may otherwise threaten the likelihood of adoption success. To this end, facilitating the adoptive families' awareness of, and access to, pre- and post-adoption supports can foster enhanced preparation. As well, it can potentially impact placement outcomes, significantly and positively. Finally, unmet service needs can critically undermine the quality and stability of adoption placements (Reilly \& Platz, 2008). The task of identifying any service needs and gaps in service delivery is therefore essential to ensuring safe, healthy, and successful adoptive experiences for children and youth with special needs. 


\section{REFERENCES}

Adoptive Families Association of BC (2014). About Adoption. Retrieved March 27, 2014, from https://www.bcadoption.com/aboutadoption

Barth, R., Berry, M., Yoshikami, R., Goodfield, R., \& Carson, M. (1988). Predicting adoption disruption. Social Work, 33(3), 227-233.

Berry, M., Propp, J., \& Martens, P. (2007). The use of intensive family preservation services with adoptive families. Child \& Family Social Work, 12(1), 43-53. http://dx.doi.org/10.1111/j.1365-2206.2006.00426.x

Denby, R., Alford, K., \& Ayala, J. (2011). The journey to adopt a child who has special needs: Parents' perspectives. Children \& Youth Services Review, 33(9), 1543-1554. http://dx.doi.org/10.1016/j.childyouth.2011.03.019

Egbert, S. \& Lamont, E. (2004). Factors contributing to parents' preparation for special-needs adoption. Child \& Adolescent Social Work fournal, 21(6), 593-609. http://dx.doi.org/10.1007/s10560-004-6406-4

Erich, S. \& Leung, P. (2002). The impact of previous type of abuse and sibling adoption upon adoptive families. Child Abuse \& Neglect, 26(10), 1045. http://dx.doi.org/10.1016/s0145-2134(02)00374-5

Glidden, L., Flaherty, E., \& McGlone, A. P. (2000). Is more too many? Adjustment in families with adopted Children with developmental disabilities. Adoption Quarterly, 4(1), 67-80. http://dx.doi.org/10.1300/145v04n01_05

McGlone, K., Santos, L., Kazama, L., Fong, R., \& Mueller, C. (2002). Psychological stress in adoptive parents of special-needs children. Child Welfare, 81(2), 151-171.

Ministry of Children and Family Development (2014). Adoption. Retrieved August 27, 2014, from http://www.mcf.gov.bc.ca/adoption/ index.htm

Perry, C. \& Henry, M. (2009). Family and professional considerations for adoptive parents of children with special needs. Marriage \& Family Review, 45(5), 538-565. http://dx.doi.org/10.1080/01494920903050938

Reilly, T. \& Platz, L. (2004). Post-adoption service needs of families with special needs children: Use, helpfulness, and unmet needs. Fournal Of Social Service Research, 30(4), 51-67. $\begin{array}{r}\text { http://dx.doi.org/10.1300/ } \\ \text { j079v30n04_03 }\end{array}$

Rosenthal, J. \& Groze, V. (1994). A longitudinal study of special-needs 
adoptive families. Child Welfare, 73(6), 689-706.

Rosenthal, J., Groze, V., \& Morgan, J. (1996). Services for families adopting children via public child welfare agencies: Use, helpfulness, and need. Children And Youth Services Review, 18(1-2), 163182. http://dx.doi.org/10.1016/0190-7409(95)00059-3

Simmel, C. (2007). Risk and protective factors contributing to the longitudinal psychosocial well-being of adopted foster children. Journal Of Emotional \& Behavioral Disorders, 15(4), 237-249. ${ }_{/ 10634266070150040501}^{\text {htp:/d.doi.r/10.117 }}$

Westhues, A., \& Cohen, J. (1990). Preventing disruption of specialneeds adoptions. Child Welfare, 69(2), 141-155.

Yampolskaya, S., Sharrock, P., Armstrong, M., Strozier, A., \& Swanke, J. (2014). Profile of children placed in out-of-home care: Association with permanency outcomes. Children \& Youth Services Review, 36, 195-200. http://dx.doi.org/10.1016/j.childyouth.2013.11.018

Zosky, D., Howard, J., Smith, S., Howard, A., \& Shelvin, K. (2005). Investing in adoptive families: What adoptive families tell us regarding the benefits of adoption preservation services. Adoption Quarterly, 8(3), 1-23. http://dx.doi.org/10.1300/j145v08n03_01 